\title{
A superactive leptin antagonist alters metabolism and locomotion in high-leptin mice
}

\author{
Nava Chapnik, Gili Solomon, Yoni Genzer, Ruth Miskin', Arieh Gertler and Oren Froy \\ Robert H. Smith Faculty of Agriculture, Food and Environment, Institute of Biochemistry, Food Science and \\ Nutrition, The Hebrew University of Jerusalem, Rehovot 76100, Israel \\ ${ }^{1}$ Department of Biological Chemistry, Weizmann Institute of Science, Rehovot 76100, Israel
}

Correspondence should be addressed to O Froy

Email

oren.froy@mail.huji.ac.il

\begin{abstract}
Transgenic alpha murine urokinase-type plasminogen activator ( $\alpha$ MUPA) mice are resistant to obesity and their locomotor activity is altered. As these mice have high leptin levels, our objective was to test whether leptin is responsible for these characteristics. MMUPA, their genetic background control (FVB/N), and C57BL mice were injected s.c. every other day with $20 \mathrm{mg} / \mathrm{kg}$ pegylated superactive mouse leptin antagonist (PEG-SMLA) for 6 weeks. We tested the effect of PEG-SMLA on body weight, locomotion, and bone health. The antagonist led to a rapid increase in body weight and subsequent insulin resistance in all treated mice. Food intake of PEG-SMLA-injected animals increased during the initial period of the experiment but then declined to a similar level to that of the control animals. Interestingly, $\alpha$ MUPA mice were found to have reduced bone volume (BV) than FVB/N mice, although PEG-SMLA increased bone mass in both strains. In addition, PEG-SMLA led to disrupted locomotor activity and increased corticosterone levels in C57BL but decreased levels in $\alpha$ MUPA or FVB/N mice. These results suggest that leptin is responsible for the lean phenotype and reduced $B V$ in aMUPA mice; leptin affects corticosterone levels in mice in a strain-specific manner; and leptin alters locomotor activity, a behavior determined by the central circadian clock.
\end{abstract}
Key Words
- $\alpha$ MUPA
- PEG-SMLA
- leptin
- antagonist
- bone
- locomotor
- obesity

\section{Introduction}

Alpha murine urokinase-type plasminogen activator ( $\alpha$ MUPA) mice carry as a transgene the cDNA-encoding uPA linked to the enhancer-promoter region of the $\alpha$ A-crystalline gene (Miskin et al. 1990). uPA is an extracellular serine protease that plays a role in fibrinolysis and tissue remodeling (Mondino \& Blasi 2004) and has been implicated in brain development, synaptic plasticity, and neuroprotection (Del Bigio et al. 1999, Cho et al. 2012). aMUPA mice show transgenic expression in the ocular lens, as expected from the promoter specificity, however also ectopic expression specifically in the brain and developing teeth (Miskin et al. 2005, 2006). aMUPA mice display a set of phenotypic behavioral and metabolic alterations, such as reduced food intake and body weight, resistance to obesity, increased life span, reduced incidence of cancerous lesions, and reduced serum levels of insulin-like growth factor 1 (IGF1; Miskin et al. 2005, Tirosh et al. 2005). In addition, these mice have increased serum levels of the anorexigenic hormones insulin and leptin and low serum levels of the orexigenic hormone ghrelin, along with increased transcript levels of anorexigenic neuropeptides and decreased levels of orexigenic neuropeptides in the brain (Froy et al. 2011). aMUPA mice also show pronounced circadian rhythms (Froy et al. 2006)

Published by Bioscientifica Ltd 
and altered locomotor activity compared with FVB/N mice (Gutman et al. 2011).

aMUPA mice that spontaneously consume less food per day $(\sim 25 \%)$ have many of the aforementioned health-related features of mice treated with caloric restriction (CR; Speakman \& Mitchell 2011). However, CR-treated animals differ from $\alpha$ MUPA mice as they have low serum levels of leptin and insulin and high levels of ghrelin (Speakman \& Mitchell 2011). Previous studies have shown that CR during rapid skeletal growth is deleterious to both cortical and trabecular bone mass and architecture (Devlin et al. 2010). In mice between the ages of 2.5 and 8.5 months, CR decreases femur cortical bone mass but maintains or increases trabecular bone mass, effects thought to be linked to the low leptin levels (Hamrick et al. 2008). Likewise, CR decreases tibiae trabecular bone mass until 1 year of age mainly through a leptinmediated suppression of bone formation, whereas CR for more than 2 years has a protective effect against age-related bone loss through reducing the rate of bone turnover (Tatsumi et al. 2008). The effect of high leptin levels on bone health has never been studied in $\alpha$ MUPA mice.

We hypothesize that some of the aforementioned differences between $\alpha$ MUPA and FVB/N mice could be mediated by high aMUPA leptin levels, in particular, the satiated, lean phenotype, resistance to obesity, and the alterations in locomotor activity. As leptin is involved in bone metabolism (Hamrick 2004, Karsenty \& Oury 2010), we hypothesize that $\alpha$ MUPA mice could also differ in bone properties from $\mathrm{FVB} / \mathrm{N}$ mice. Therefore, our aim was to examine the involvement of leptin in these aspects of the aMUPA phenotype. We used a recently developed pegylated superactive mouse leptin antagonist (PEGSMLA; Shpilman et al. 2011), and compared aMUPA mice, their $\mathrm{FVB} / \mathrm{N}$ control, and $\mathrm{C} 57 \mathrm{BL}$ mice that are more commonly used in metabolic studies.

\section{Materials and methods}

\section{Animal treatments}

Five-month-old $\alpha$ MUPA ( $n=7-9$ ) and FVB/N (wild-type (WT)) mice ( $n=7-9)$ (obtained from the Weizmann Institute of Science, Rehovot, Israel) and C57BL mice $(n=8$; Harlan, Jerusalem, Israel) were housed in a facility with controlled temperature $\left(20-22^{\circ} \mathrm{C}\right)$ and humidity (60\%) under a $12 \mathrm{~h}$ light:12 $\mathrm{h}$ darkness (LD) cycle with regular chow available ad libitum. After 2 weeks of acclimation, mice were injected s.c. every other day with
$20 \mathrm{mg} / \mathrm{kg}$ per day PEG-SMLA for 6 weeks, 2 weeks in LD, 2 weeks in total darkness (DD), and 2 weeks in LD. PEG-SMLA was expressed, purified, and monopegylated as was described previously (Shpilman et al. 2011). Food intake and body weight were monitored throughout the experiment. On the last day of the experiment, mice were fasted for $10 \mathrm{~h}$. Subsequently, mice were anesthetized with isoflurane and blood was collected. At the time of blood collection, fasting blood glucose levels were determined using a glucometer (Optium Xceed; Abbott Laboratories). Total fat content was determined by weighing abdominal fat pads. The Joint Ethics Committee (IACUC) of the Hebrew University and Hadassah Medical Center approved the study protocol for animal welfare. The Hebrew University is an AAALAC International accredited institute.

\section{Homeostasis model assessment of insulin resistance}

The insulin-resistance index from fasting serum insulin and plasma glucose levels was determined by the homeostasis model assessment of insulin resistance (HOMA-IR) parameter: HOMA = fasting serum insulin $(\mu \mathrm{U} / \mathrm{ml}) \times$ fasting plasma glucose $(\mathrm{mg} / \mathrm{dl}) / 405$.

\section{Serum separation and ELISA}

Blood was kept at room temperature for $30 \mathrm{~min}$ for clotting and consequently centrifuged at $2000 \mathrm{~g}$ for $15 \mathrm{~min}$ at $4{ }^{\circ} \mathrm{C}$. Serum was collected and stored at $-20^{\circ} \mathrm{C}$ for further analysis. Serum hormone levels were determined for insulin (Mercodia, Uppsala, Sweden), corticosterone (Assaypro, St Charles, MO, USA), IL6, and TNF $\alpha$ (R\&D Systems, Inc., Minneapolis, MN, USA) using ELISA Kits. Assays were performed according to the manufacturers' instructions.

\section{Animal locomotor activity}

General cage activity was monitored continuously at 6-min intervals using a custom-made system composed of infrared detectors placed above each cage, as was previously described (Gutman et al. 2011). Cage locomotor activity was recorded continuously under LD conditions for 14 days after which mice were released to DD for 14 days and then again to LD for 14 days. Double-plotted actograms were generated using Actogram Software. Period length of circadian activity rhythms in DD (tau) was calculated individually by $\chi^{2}$ analyses using Tau Software. Actogram and Tau Softwares were kindly provided by Refinetti R, University of South Carolina.

Published by Bioscientifica Ltd 


\section{Micro-CT analysis of third lumbar vertebrae}

Third lumbar vertebrae (LV3) were scanned with a Skyscan 1174 X-ray computed microtomograph scanner (Skyscan, Aartselaar, Belgium), equipped with a ChargeCouple Device (CCD) detector. Images were obtained by $50 \mathrm{kV}$ X-ray tube voltages and $800 \mathrm{~mA}$ current, $0.25 \mathrm{~mm}$ aluminum filter, at $4300 \mathrm{~ms}$ exposure time, and 11.1 pixel size resolution were used. For each specimen, a series of 900 projection images were obtained with a rotation step of $0.4^{\circ}$, averaging two frames, for a total $360^{\circ}$ rotation. Flat field correction was performed at the beginning of each scan for a specific zoom and image format. A stack of $2 \mathrm{D}$ X-ray shadow projections was reconstructed to obtain images using NRecon Software (Skyscan) and subjected to the morphometric analysis using CTAn Software (Skyscan). During reconstruction, dynamic image range, post-alignment value, beam hardening, and ring-artifact reduction were optimized. For analysis of the Lumbar vertebrae LV3 trabecular region, a total of 150 slices, corresponding to $1.665 \mathrm{~mm}$ were selected and adaptive gray-scale threshold levels between 60 and 255 were used. Analysis of the lumbar vertebrae included the entire region of the vertebrae body. Trabecular bone measurements in the lumbar vertebra included trabecular bone volume (BV)/tissue volume (TV) (\%), trabecular number (Tb.N; $1 / \mu \mathrm{m})$, trabecular thickness (Tb.Th; $\mu \mathrm{m})$, and trabecular separation (Tb.Sp; $\mu \mathrm{m}$ ). Morphometric analysis was based on the 2D and 3D internal CTAn plug-ins. 3D images (CTM file format) were constructed from cortical and trabecular regions of interest, using Marching Cubes 33 algorithm in CTVol Software (Skyscan).

\section{Statistical analysis}

Student's t-test was used for comparison within mouse strains. All results are expressed as means \pm s.e.M. For all analyses, the significance level was set at $P<0.05$. Statistical analysis was performed with JMP Software (version 5.1; SAS Institute, Inc., Cary, NC, USA).

\section{Results}

We examined the impact of a PEG-SMLA on weight gain, bone health, and locomotor activity in naturally lean aMUPA mice, which express high leptin levels. $\alpha$ MUPA mice were compared to $\mathrm{FVB} / \mathrm{N}$ mice, their WT genetic background, and to $\mathrm{C} 57 \mathrm{BL}$ mice. All three strains were compared to their corresponding saline-injected mice. To test the effect on locomotor activity, the effect of
PEG-SMLA was performed for 6 weeks, 2 weeks in light-dark (LD1), 2 weeks in total darkness (DD), and then 2 weeks in LD (LD2).

\section{Effect of PEG-SMLA on body weight and food intake}

PEG-SMLA led to immediate increased food intake (Fig. 1A) and body weight (Fig. 1B) in $\alpha M U P A, F V B / N$, and C57BL compared with saline-injected mice. Although aMUPA mice started with a typical lower body weight compared with WT FVB/N mice of the same age, their weight gain during the first LD period (LD1) was higher than that of $\mathrm{FVB} / \mathrm{N}$ or C57BL mice ( $\sim 37 \%$ compared to $\sim 34 \%$; Fig. 1C). Corresponding to their increased body weight, all strains showed increased abdominal fat pads, with aMUPA showing the highest (Fig. 1D), as expected from the initial increase during the LD1 period. The main weight gain was achieved during the first 2 weeks and continued, but at a lower pace, throughout the last 4 weeks. In parallel, food intake was much higher during the first week in all three strains and started to decline thereafter resembling that of the control mice (Fig. 1A). After 6 weeks, the amount of food intake was only slightly higher in the PEG-SMLA- vs saline-injected mice in the three strains, although major differences in body weight were maintained (Fig. 1A and B).

\section{Effect of PEG-SMLA on serum parameters}

We next examined serum parameters to characterize the weight gain status of the PEG-SMLA-injected mice. Glucose levels were higher in the PEG-SMLA- vs salineinjected mice, showing glucose intolerance (Fig. 2A). Also, insulin levels were higher in the PEG-SMLA-injected mice (Fig. 2B) yielding, together with the high glucose levels, a high insulin resistance index (HOMA-IR; Fig. 2C). We next analyzed whether mice in this experimental treatment were normal (glucose and insulin are $<1.96$ s.D. above control average), insulin-resistant (insulin level is higher than 1.96 s.D. above control average, but glucose is $<1.96$ s.D. above control average), or have developed type 2 diabetes mellitus (both insulin and glucose are higher than 1.96 s.D. above control average). This analysis showed that in all three strains, almost all mice injected with PEG-SMLA had above the critical level of insulin (Supplementary Fig. 1A, B and C, see section on supplementary data given at the end of this article). Determination of glucose showed that one out of seven and four out of seven of the mice injected with PEG-SMLA were slightly above the corresponding glucose critical level

Published by Bioscientifica Ltd 

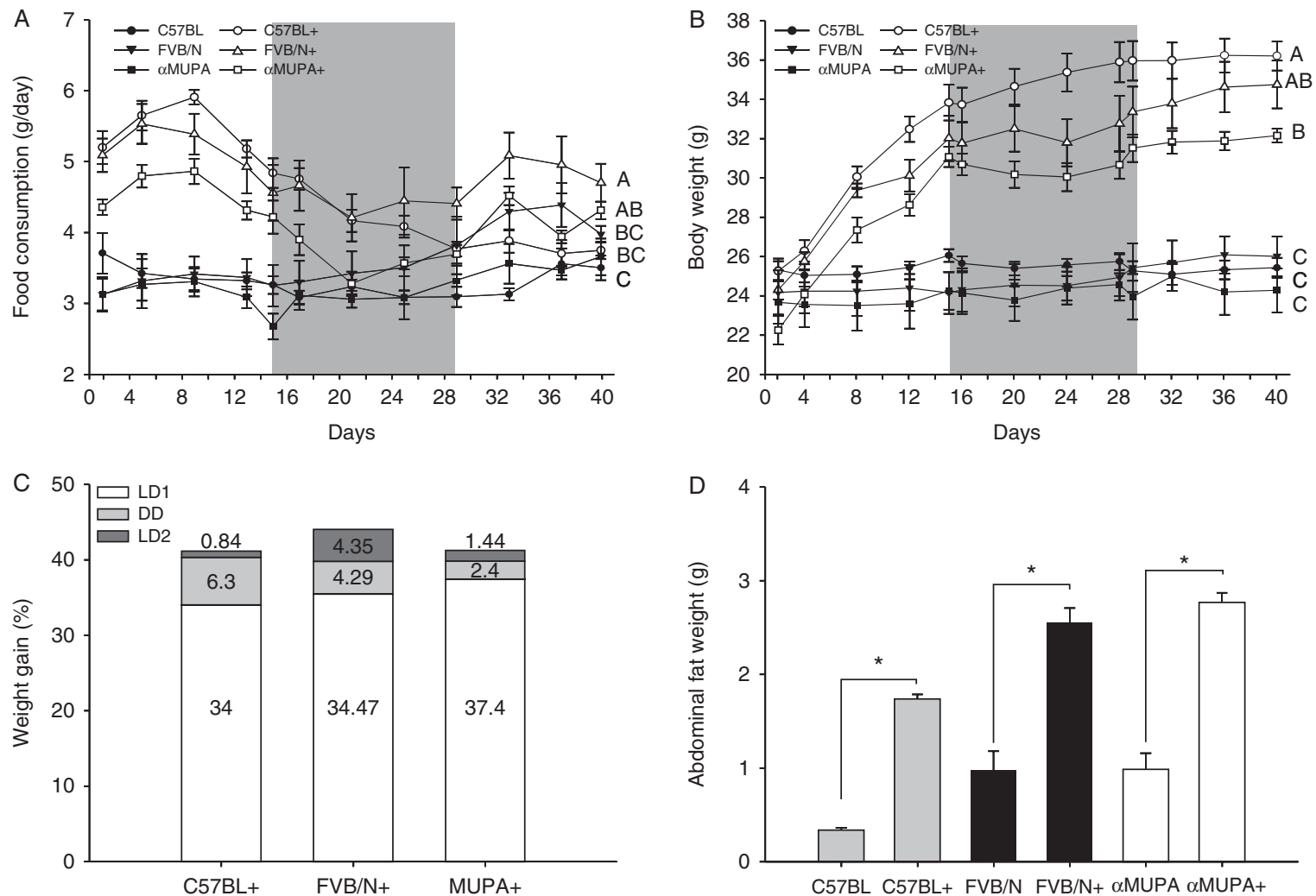

Figure 1

Body weight, weight gain, food consumption, and fat depots of C57BL, aMUPA, and FVB/N mice injected with PEG-SMLA or saline. (A) Food consumption. (B) Weekly mean body weight. (C) Weight gain (\%).

in $\alpha \mathrm{MUPA}$ and $\mathrm{FVB} / \mathrm{N}$ mice respectively while almost all C57BL mice were slightly above the critical level (Supplementary Fig. 1D, E and F). No correlation was found between the weight gain and the insulin level in all three mouse strains treated with PEG-SMLA (not shown). Analysis of two obesity pro-inflammatory markers, IL6 and $\mathrm{TNF} \alpha$, revealed no increased blood levels in all three strains (not shown). However, corticosterone levels were approximately sixfold higher in PEG-SMLA-injected C57BL mice, but lower, approximately sixfold or twoto threefold fold in $\alpha \mathrm{MUPA}$ or $\mathrm{FVB} / \mathrm{N}$ mice respectively (Fig. 2D).

\section{Effect of PEG-SMLA on locomotor activity}

We next compared the effect of PEG-SMLA on daily locomotor activity during LD1 and LD2. PEG-SMLA caused reduced activity in both periods (Fig. 3). To test the effect on the period of the circadian clock, mice were placed under DD condition. Analysis of the period (tau) revealed no significant difference as a result of

(D) Abdominal fat tissue mass. Data are means \pm S.E.M.; $n=7-9 /$ group; asterisks denote significant difference $(P<0.05) ;+$ designates PEG-SMLA-injected mice. The gray bar represents the DD period.

PEG-SMLA injection (Supplementary Fig. 2, see section on supplementary data given at the end of this article).

\section{Effect of PEG-SMLA on bone health}

As leptin inhibits bone accrual and $\alpha$ MUPA have high leptin levels, we measured the effect of PEG-SMLA on bone health. Interestingly, the BV/TV and Tb.Sp were lower in aMUPA mice compared with their WT FVB/N mice even in the saline-injected mice (Table 1). As a result of PEG-SMLA treatment, the thickness of a single trabecula (Tb.Th) did not change, but in most cases, the number of trabeculae per tissue area (Tb.N) increased. Owing to this increase, the $\mathrm{BV} / \mathrm{TV}$, which is the most important parameter in bone health, also increased, whereas the Tb.Sp consequently decreased (Table 1).

\section{Discussion}

In this study, we took advantage of a recently developed leptin antagonist, PEG-SMLA (Shpilman et al. 2011), to

Published by Bioscientifica Ltd. 
A

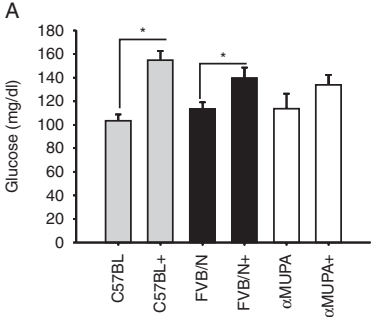

C

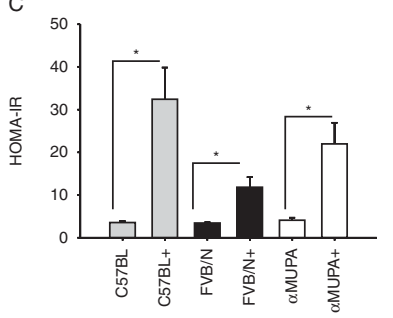

B
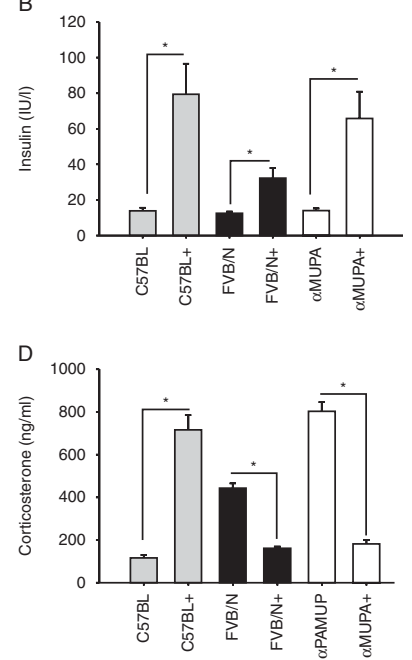

Figure 2

Serum glucose and hormone levels of C57BL, aMUPA, and FVB/N mice injected with PEG-SMLA or saline. (A) Glucose. (B) Insulin. (C) HOMA-IR. (D) Corticosterone. Data are means \pm s.E.M.; $n=7-9 /$ group; asterisks denote significant difference $(P<0.05) ;+$ designates PEG-SMLA-injected mice.

examine the extent in which leptin is responsible for several phenotypic features exhibited by $\alpha$ MUPA mice that express high levels of this adipokine. We found that a superactive leptin antagonist leads to fast increased body weight. In addition, we also found that it leads to disrupted locomotor activity and increased corticosterone secretion in C57BL mice but not in $\alpha$ MUPA or FVB/N mice.

PEG-SMLA has recently been shown to lead to $\sim 40 \%$ increase in body weight (Shpilman et al. 2011). However, PEG-SMLA injection led to weight gain in aMUPA mice, shown previously to have higher leptin levels than their genetic background (Froy et al. 2011) and to be resistant to obesity throughout their lifetime (Froy \& Miskin 2010). Weight gain induction in $\alpha$ MUPA mice suggests that these mice are lean due to the high leptin levels. The results also suggest that $\alpha$ MUPA mice are protected against leptin resistance, a state that appears under chronic increase in leptin (Halaas et al. 1997), such as during obesity (Montague et al. 1997). Interestingly, FVB/N mice, which have been used as a diet-induced obesityresistant model (Kim et al. 2012), also became obese, suggesting that these mice are not resistant to leptin antagonist-induced weight gain. Surprisingly, we found that the weight gain seen in all mice was associated with increased food intake only during the first week of PEG-SMLA injection, but decreased to levels only slightly higher than those consumed by saline-injected mice. These results can be explained by the fact that initial

PEG-SMLA injection led to increased hunger and that, in turn, led to increased food intake. However, the secondary effect of PEG-SMLA may have been to relieve the inhibition of corticosterone secretion mediated by leptin (Malendowicz et al. 2007). In C57BL mice, the high levels of corticosterone could have led to increased differentiation to fat tissue (Madsen et al. 2005), which led to elevated body weight without increased food intake. However, in aMUPA and FVB/N mice, suppressed corticosterone secretion was seen as a result of PEG-SMLA injection. Our results suggest that primary and secondary effects on corticosterone secretion after PEG-SMLA injection in mice are strain specific and reminiscent of the findings in rats (Hochol et al. 2000, Malendowicz et al. 2007). Determination of 1.96 s.D. insulin and glucose levels suggested that all PEG-SMLA-treated mice have developed insulin resistance after 6 weeks of injection. However, only one out of seven $\alpha$ MUPA and four out of seven FVB/N mice, but almost all C57BL mice, were marginally diabetic. It should also be noted that the PEG-SMLA treatment that led to insulin resistance was not accompanied by inflammation in contrast with mice kept on high-fat diet (Sherman et al. 2011).

In all three strains, we found that PEG-SMLA injection led to decreased locomotor activity. As the circadian clock in the hypothalamus suprachiasmatic nuclei (SCN) controls rhythms of locomotor activity and this brain area has been shown to have leptin receptors (Guan et al. 1997, Yi et al. 2006), our results suggest that a leptin antagonist may counteract the effect of leptin on the SCN clock. Indeed, it has recently been shown that leptin potentiated the phase-shifting effect of a 30-min light pulse on behavioral rhythms during the late subjective night in female mice (Mendoza et al. 2011). In contrast to our results, it was found that a 2 -week chronic exposure to a physiological dose of leptin $(100 \mu \mathrm{g} / \mathrm{kg}$ per day) decreased locomotor activity (Mendoza et al. 2011). As obesity itself has been shown to also affect locomotor activity (Kohsaka et al. 2007, Sherman et al. 2011), it is possible that leptin resistance, a characteristic of obesity, is the reason for the disrupted locomotor activity.

Our results show that $\alpha$ MUPA mice have a more reduced BV than their WT genetic background. aMUPA display several characteristics common to CR-treated animals, such as reduced food intake, increased longevity, reduced body temperature, reduced levels of serum IGF1, increased levels of mitochondrion-mediated apoptosis, and reduced incidence of spontaneous and induced cancerous lesions (Tirosh et al. 2003, 2005, Miskin et al. 2005). However, the reduced BV found in $\alpha$ MUPA mice are inconsistent with CR-treated mice,

Published by Bioscientifica Ltd. 
A

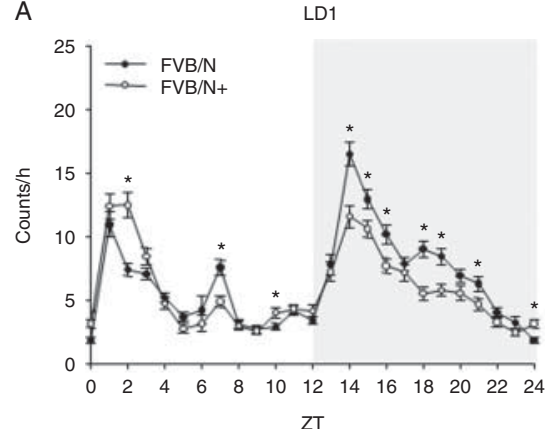

B

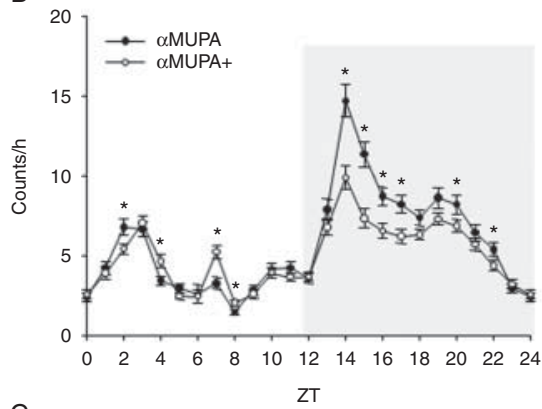

C

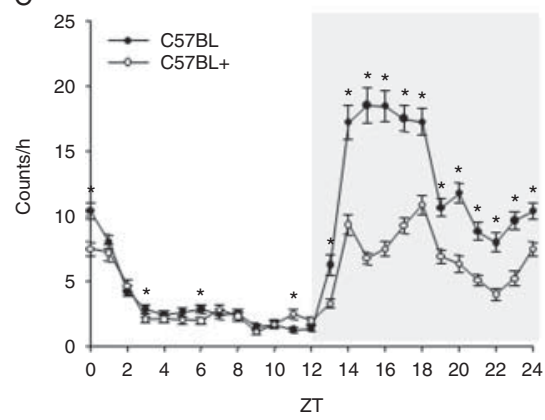

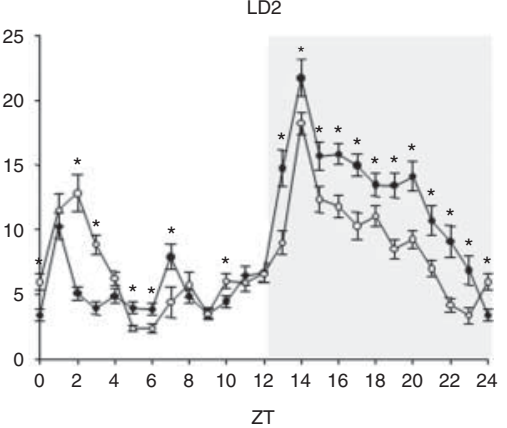
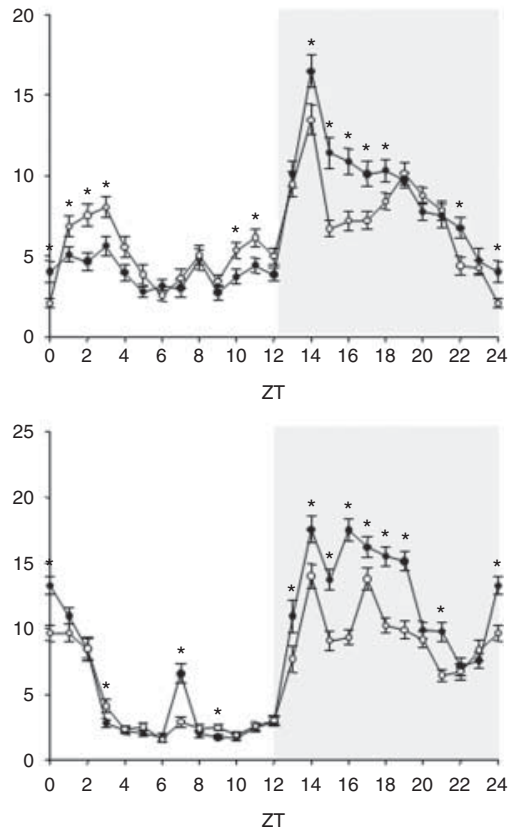

\section{Figure 3}

Locomotor activity of C57BL6, $\alpha$ MUPA, and FVB/N mice injected with PEG-SMLA or saline. (A) Mean locomotor activity of FVB/N mice. (B) Mean locomotor activity of $\alpha$ MUPA mice. (C) Mean locomotor activity of C57BL mice. Results are mean activity during the last 14 days of LD1 or LD2 period.

as previous studies show that CR preserves or increases trabecular BV (Hamrick et al. 2008) and retards age-related bone loss in aged animals (Pendergrass et al. 1995, Tatsumi et al. 2008). As low levels of leptin lead to improved bone
Values are means +s.E.M.; $n=7-9 /$ group; shaded area designates the darkness phase; asterisks denote significant difference $(P<0.05)$; + designates PEG-SMLA-injected mice.

health (Hamrick 2004, Karsenty \& Oury 2010), the high leptin levels in $\alpha$ MUPA mice may account for their reduced $\mathrm{BV}$. This also corroborates our findings that the PEG-SMLA injection led to significantly increased $\mathrm{BV}$ in $\mathrm{FVB} / \mathrm{N}$ mice and

Table 1 Bone parameters of saline- vs PEG-SMLA-injected $\alpha$ MUPA and FVB/N mice. Results are mean \pm s.E.M. $(n=7-9)$

\begin{tabular}{|c|c|c|c|c|}
\hline & $\begin{array}{c}\text { Saline-injected } \\
\text { FVB/N }\end{array}$ & $\begin{array}{c}\text { PEG-SMLA-injected } \\
\text { FVB/N }\end{array}$ & $\begin{array}{c}\text { Saline-injected } \\
\alpha \text { MUPA }\end{array}$ & $\begin{array}{c}\text { PEG-SMLA-injected } \\
\text { aMUPA }\end{array}$ \\
\hline $\begin{array}{l}\text { BV/TV }(\%) \\
\text { Tb.Th }(\mu \mathrm{m}) \\
\text { Tb.Sp }(\mu \mathrm{m}) \\
\text { Tb.N }(1 / \mu \mathrm{m})\end{array}$ & $\begin{array}{l}15.6 \pm 1.07^{b} \\
0.07 \pm 0.001^{a} \\
0.34 \pm 0.01^{b, c} \\
2.15 \pm 0.13^{a, b}\end{array}$ & $\begin{array}{c}19.75 \pm 1.15^{\mathrm{a}} \\
0.07 \pm 0.0008^{\mathrm{a}} \\
0.30 \pm 0.01^{\mathrm{c}} \\
2.62 \pm 0.14^{\mathrm{a}}\end{array}$ & $\begin{array}{l}11.9 \pm 0.64^{\mathrm{c}} \\
0.07 \pm 0.001^{\mathrm{a}} \\
0.44 \pm 0.02^{\mathrm{a}} \\
1.64 \pm 0.09^{\mathrm{b}}\end{array}$ & $\begin{array}{l}13.3 \pm 0.86^{\mathrm{b}, \mathrm{c}} \\
0.07 \pm 0.00^{\mathrm{a}} \\
0.40 \pm 0.02^{\mathrm{a}, \mathrm{b}} \\
1.76 \pm 0.11^{\mathrm{b}}\end{array}$ \\
\hline
\end{tabular}

Results marked with the same letter are not statistically different.

http://joe.endocrinology-journals.org DOI: 10.1530/JOE-13-0033
() 2013 Society for Endocrinology Printed in Great Britain
Published by Bioscientifica Ltd. 
to a higher although not significant BV/TV in $\alpha$ MUPA mice. These results are also corroborated by other findings that show increased bone formation in C57BL mice after PEGSMLA treatment (Solomon, Gertler, and Ornan-Monsonego, unpublished results). In addition, the elevated levels of corticosterone in aMUPA mice could also account for the reduced $\mathrm{BV}$.

In summary, after applying a powerful leptin antagonist, we conclude that the endogenous high leptin levels found in $\alpha$ MUPA mice are responsible to a large extent for their reduced food intake, lean phenotype, resistance to obesity, and weak bones. Also, the effect of the antagonist, and therefore of leptin, on corticosterone serum levels is strain specific in mice. As the leptin antagonist leads to decreased locomotor activity in all three mouse strains tested, our results also support a leptin action on the SCN clock. Thus, a high-leptin model with an antagonist that induces weight gain without having to use high-fat diet may be used in future studies to decipher the effect of leptin on metabolism, bone health, and the circadian clock.

\section{Supplementary data}

This is linked to the online version of the paper at http://dx.doi.org/10.1530/ JOE-13-0033.

\section{Declaration of interest}

The authors declare that there is no conflict of interest that could be perceived as prejudicing the impartiality of the research reported.

\section{Funding}

This research did not receive any specific grant from any funding agency in the public, commercial or not-for-profit sector.

\section{References}

Cho E, Lee KJ, Seo JW, Byun CJ, Chung SJ, Suh DC, Carmeliet P, Koh JY, Kim JS \& Lee JY 2012 Neuroprotection by urokinase plasminogen activator in the hippocampus. Neurobiology of Disease 46 215-224. (doi:10.1016/j.nbd.2012.01.010)

Del Bigio MR, Hosain S \& Altumbabic M 1999 Localization of urokinasetype plasminogen activator, its receptor, and inhibitors in mouse forebrain during postnatal development. International Journal of Developmental Neuroscience 17 387-399. (doi:10.1016/S0736-5748 (99)00031-3)

Devlin MJ, Cloutier AM, Thomas NA, Panus DA, Lotinun S, Pinz I, Baron R, Rosen CJ \& Bouxsein ML 2010 Caloric restriction leads to high marrow adiposity and low bone mass in growing mice. Journal of Bone and Mineral Research 25 2078-2088. (doi:10.1002/jbmr.82)

Froy O \& Miskin R 2010 Effect of feeding regimens on circadian rhythms: implications for aging and longevity. Aging 2 7-27.

Froy O, Chapnik N \& Miskin R 2006 Long-lived $\alpha$ MUPA transgenic mice exhibit pronounced circadian rhythms. American Journal of Physiology.

http://joe.endocrinology-journals.org DOI: $10.1530 / J O E-13-0033$
(C) 2013 Society for Endocrinology Printed in Great Britain
Endocrinology and Metabolism 291 E1017-E1024. (doi:10.1152/ajpendo. 00140.2006)

Froy O, Sherman H, Bhargava G, Chapnik N, Cohen R, Gutman R, Kronfeld-Schor N \& Miskin R 2011 Spontaneous caloric restriction associated with increased leptin levels in obesity-resistant $\alpha$ MUPA mice. International Journal of Obesity 35 226-235. (doi:10.1038/ ijo.2010.125)

Guan XM, Hess JF, Yu H, Hey PJ \& van der Ploeg LH 1997 Differential expression of mRNA for leptin receptor isoforms in the rat brain. Molecular and Cellular Endocrinology 133 1-7. (doi:10.1016/ S0303-7207(97)00138-X)

Gutman R, Genzer Y, Chapnik N, Miskin R \& Froy O 2011 Long-lived mice exhibit $24 \mathrm{~h}$ locomotor circadian rhythms at young and old age. Experimental Gerontology 46 606-609. (doi:10.1016/j.exger.2011. 02.015)

Halaas JL, Boozer C, Blair-West J, Fidahusein N, Denton DA \& Friedman JM 1997 Physiological response to long-term peripheral and central leptin infusion in lean and obese mice. PNAS 94 8878-8883. (doi:10.1073/ pnas.94.16.8878)

Hamrick MW 2004 Leptin, bone mass, and the thrifty phenotype. Journal of Bone and Mineral Research 19 1607-1611. (doi:10.1359/JBMR.040712)

Hamrick MW, Ding KH, Ponnala S, Ferrari SL \& Isales CM 2008 Caloric restriction decreases cortical bone mass but spares trabecular bone in the mouse skeleton: implications for the regulation of bone mass by body weight. Journal of Bone and Mineral Research 23 870-878. (doi:10.1359/jbmr.080213)

Hochol A, Nowak KW, Belloni AS, Nussdorfer GG \& Malendowicz LK 2000 Effects of leptin on the response of rat pituitary-adrenocortical axis to ether and cold stresses. Endocrine Research 26 129-140. (doi:10.3109/ 07435800009066157)

Karsenty G \& Oury F 2010 The central regulation of bone mass, the first link between bone remodeling and energy metabolism. Journal of Clinical Endocrinology and Metabolism 95 4795-4801. (doi:10.1210/ jc.2010-1030)

Kim DH, Gutierrez-Aguilar R, Kim HJ, Woods SC \& Seeley RJ 2013 Increased adipose tissue hypoxia and capacity for angiogenesis and inflammation in young diet-sensitive C57 mice compared with diet-resistant FVB mice. International Journal of Obesity. In press.

Kohsaka A, Laposky AD, Ramsey KM, Estrada C, Joshu C, Kobayashi Y, Turek FW \& Bass J 2007 High-fat diet disrupts behavioral and molecular circadian rhythms in mice. Cell Metabolism 6 414-421. (doi:10.1016/ j.cmet.2007.09.006)

Madsen L, Petersen RK \& Kristiansen K 2005 Regulation of adipocyte differentiation and function by polyunsaturated fatty acids. Biochimica et Biophysica Acta 1740 266-286. (doi:10.1016/j.bbadis.2005.03.001)

Malendowicz LK, Rucinski M, Belloni AS, Ziolkowska A \& Nussdorfer GG 2007 Leptin and the regulation of the hypothalamic-pituitary-adrenal axis. International Review of Cytology 263 63-102.

Mendoza J, Lopez-Lopez C, Revel FG, Jeanneau K, Delerue F, Prinssen E, Challet E, Moreau JL \& Grundschober C 2011 Dimorphic effects of leptin on the circadian and hypocretinergic systems of mice. Journal of Neuroendocrinology 23 28-38. (doi:10.1111/j.1365-2826.2010.02072.x)

Miskin R, Axelrod JH, Griep AE, Lee E, Belin D, Vassalli JD \& Westphal H 1990 Human and murine urokinase cDNAs linked to the murine $\alpha \mathrm{A}$-crystallin promoter exhibit lens and non-lens expression in transgenic mice. European Journal of Biochemistry 190 31-38. (doi:10.1111/j.1432-1033.1990.tb15541.x)

Miskin R, Tirosh O, Pardo M, Zusman I, Schwartz B, Yahav S, Dubnov G \& Kohen R 2005 aMUPA mice: a transgenic model for longevity induced by caloric restriction. Mechanisms of Ageing and Development 126 255-261. (doi:10.1016/j.mad.2004.08.018)

Miskin R, Masos T, Shoham Z \& Williams-Simons L 2006 Urokinase-type plasminogen activator mRNA is expressed in normal developing teeth and leads to abnormal incisor enamel in $\alpha$ MUPA transgenic mice. Transgenic Research 15 241-254. (doi:10.1007/s11248-006-0006-3) 
Mondino A \& Blasi F 2004 uPA and uPAR in fibrinolysis, immunity and pathology. Trends in Immunology 25 450-455. (doi:10.1016/j.it.2004. 06.004)

Montague CT, Farooqi IS, Whitehead JP, Soos MA, Rau H, Wareham NJ, Sewter CP, Digby JE, Mohammed SN, Hurst JA et al. 1997 Congenital leptin deficiency is associated with severe early-onset obesity in humans. Nature 387 903-908. (doi:10.1038/43185)

Pendergrass WR, Li Y, Jiang D, Fei RG \& Wolf NS 1995 Caloric restriction: conservation of cellular replicative capacity in vitro accompanies life-span extension in mice. Experimental Cell Research 217 309-316. (doi:10.1006/excr.1995.1091)

Sherman H, Frumin I, Gutman R, Chapnik N, Lorentz A, Meylan J, le Coutre J \& Froy O 2011 Long-term restricted feeding alters circadian expression and reduces the level of inflammatory and disease markers. Journal of Cellular and Molecular Medicine 15 2745-2759. (doi:10.1111/ j.1582-4934.2010.01160.x)

Shpilman M, Niv-Spector L, Katz M, Varol C, Solomon G, Ayalon-Soffer M, Boder E, Halpern Z, Elinav E \& Gertler A 2011 Development and characterization of high affinity leptins and leptin antagonists. Journal of Biological Chemistry 286 4429-4442. (doi:10.1074/jbc.M110.196402)
Speakman JR \& Mitchell SE 2011 Caloric restriction. Molecular Aspects of Medicine 32 159-221. (doi:10.1016/j.mam.2011.07.001)

Tatsumi S, Ito M, Asaba Y, Tsutsumi K \& Ikeda K 2008 Life-long caloric restriction reveals biphasic and dimorphic effects on bone metabolism in rodents. Endocrinology 149 634-641. (doi:10.1210/en. 2007-1089)

Tirosh O, Aronis A, Zusman I, Kossoy G, Yahav S, Shinder D, Abramovitz R \& Miskin R 2003 Mitochondrion-mediated apoptosis is enhanced in long-lived $\alpha$ MUPA transgenic mice and calorically restricted wild-type mice. Experimental Gerontology 38 955-963. (doi:10.1016/S05315565(03)00151-7)

Tirosh O, Pardo M, Schwartz B \& Miskin R 2005 Long-lived $\alpha$ MUPA transgenic mice show reduced SOD2 expression, enhanced apoptosis and reduced susceptibility to the carcinogen dimethylhydrazine. Mechanisms of Ageing and Development 126 1262-1273. (doi:10.1016/ j.mad.2005.07.003)

Yi CX, van der Vliet J, Dai J, Yin G, Ru L \& Buijs RM 2006 Ventromedial arcuate nucleus communicates peripheral metabolic information to the suprachiasmatic nucleus. Endocrinology 147 283-294. (doi:10.1210/ en.2005-1051)

Received in final form 27 February 2013

Accepted 12 March 2013

Accepted Preprint published online 12 March 2013 